\title{
HUBUNGAN TINGKAT PENGETAHUAN PASIEN DIARE TERHADAP SWAMEDIKASI DAN RASIONALITAS OBAT DI APOTEK KELURAHAN MENDAWAI KOTA PANGKALAN BUN
}

\author{
Bella Patria Pratiwi P.E ${ }^{1}$; Poppy Dwi Citra Jaluri ${ }^{2}$; Yogie Irawan ${ }^{3}$ \\ ${ }^{1,2,3}$ STIKes Borneo Cendekia Medika Pangkalan Bun \\ ${ }^{1}$ Email : bellapatriaa@gmail.com
}

\begin{abstract}
Abstrak
Swamedikasi merupakan salah satu bagian dari perawatan diri. Swamedikasi diartikan dengan memilih dan menggunakan obat-obatan oleh seorang individu untuk mengobati penyakit yang diderita atau mengurangi gejala tanpa pengawasan medis. Swamedikasi biasanya dilakukan untuk mengobati gejala-gejala penyakit ringan seperti diare, pusing, maag, batuk dan lain-lain. Tujuan penelitian ini adalah untuk mengetahui tingkat pengetahuan swamedikasi, rasionalitas penggunaan obat dan hubungan antara usia, pekerjaan, jenis kelamin, pendidikan terakhir dengan tingkat pengetahuan swamedikasi. Penelitian ini menggunakan metode survei cross sectional dengan sampel penelitian pada pasien diare yang akan melakukan swamedikasi sebanyak 207 responden dari tiga apotek yang berada di Kelurahan Mendawai Pangkalan Bun. Responden berusia 18-59 tahun dan dipilih dengan metode purposive sampling. Pengambilan data dilakukan melalui pengisian kuesioner yang telah diuji validitas dan reliabilitasnya. Data dianalisis dengan uji Chisquare menggunakan Statistical Product and Servicer Solution (SPSS) versi 20. Hasil penelitian menunjukkan bahwa tingkat pengetahuan swamedikasi pasien 40,1\% tergolong baik, 56,5\% tergolong sedang, dan 3,4\% tergolong buruk. Rasionalitas penggunaan obat $63 \%$ rasional dan $37 \%$ tidak rasional. Berdasarkan hasil uji Chi-square, tingkat pengetahuan swamedikasi dipengaruhi faktor demografi yaitu usia dengan nilai $(0,016)$, pendidikan terakhir dengan nilai $(0,000)$, dan pekerjaan dengan nilai $(0,000)$. Berdasarkan hasil penelitian diperoleh bahwa mayoritas tingkat pengetahuan swamedikasi terdapat pengaruh hubungan terhadap faktor demografi yaitu pada faktor usia, pendidikan terakhir dan pekerjaan.
\end{abstract}

Kata Kunci: Swamedikasi, Apotek, Pengetahuan, Rasionalitas penggunaan obat, Pangkalan Bun

Abstract

Swamedication is a part of self-care. Self-medication is defined as selecting and using drugs by an individual to treat a disease or reduce symptoms without medical supervision. Swamedication is usually performed to treat symptoms of minor illnesses such as diarrhea, dizziness, ulcers, coughs and others. The purpose of this study was to determine the level of swamedication knowledge, the rationality of drug use and the relationship among age, occupation, gender, latest education and the level of swamedication knowledge. This study used a cross sectional survey method with a sample of 207 patients with diarrhea from three pharmacies in Mendawai, Pangkalan Bun who were going to do swamedication. The respondents' age were 18-59 years and selected by purposive sampling method. The data were collected by filling in a questionnaire that had been tested for validity and reliability. Then the data were analyzed by using the Chi-square test using Statistical Product and Service Solution (SPSS) version 20. The results of thid study showed that the patients' level of swamedication knowledge was 40,1\% good, 56,5\% moderate, and 3,4\% bad. The rationality of using drugs was $63 \%$ rational and $37 \%$ irrational. Based on the results of the Chi-square test, the level of swamedication knowledge was influenced by demographic factors, namely age with a value (0,016), latest education with a value $(0,000)$, and employment with a value (0,000). Based on the results of the study, it was found that the majority of the level of swamedication knowledge had an influence on the relationship to demographic factors, namely age, latest education and occupation.

Keywords: Swamedication, Pharmacy, Knowledge, Rationality of drug use, Pangkalan Bun. 


\section{Pendahuluan}

Pelayanan kefarmasian merupakan pelayanan kesehatan yang mempunyai peran penting dalam mewujudkan kesehatan bermutu, dimana apoteker sebagai bagian dari tenaga kesehatan mempunyai tugas dan tanggung jawab dalam mewujudkan pelayanan kefarmasian yang berkualitas. Layanan kefarmasian selain menjadi tuntutan profesionalisme juga dapat dilihat sebagai faktor yang menarik minat konsumen terhadap pembelian obat di apotek. Pelayanan kefarmasian meliputi penampilan apotek, keramahan petugas, pelayanan informasi obat, ketersediaan obat, dan kecepatan pelayanan (Syukron, 2015).

Swamedikasi merupakan salah satu bagian dari perawatan diri. Swamedikasi diartikan dengan memilih dan menggunakan obatobatan oleh seorang individu untuk mengobati penyakit yang diderita atau mengurangi gejala tanpa pengawasan medis. Meskipun beberapa obat dianggap memiliki risiko yang kecil dan berguna untuk mengobati masalah kesehatan yang serius dan reaksi yang tidak diinginkan. Swamedikasi biasanya dilakukan untuk mengobati gejalagejala penyakit ringan seperti diare, pusing, nyeri, maag, batuk, pilek dan lain-lain (Alfa, 2015). Berdasarkan data dari Badan Pusat Statistik (BPS) (2014) tentang swamedikasi oleh penduduk di peroleh data dari tahun 2002 sampai dengan tahun 2014 untuk pengobatan modern sebesar $86,68 \%$, pengobatan tradisional $32,90 \%$ dan lain-lain 8,13\%. Hasil ini juga didukung oleh indikator kesehatan dari BPS yang mengatakan persentase penduduk yang mengobati sendiri sebesar $72,44 \%$ dan Persentase penduduk yang berobat jalan (pergi ke dokter) sebesar $38,21 \%$ pada tahun 2004. (Badan Pusat Statistik, 2016).

Swamedikasi harus dilakukan sesuai dengan penyakit yang dialami, pelaksanaannya sedapat mungkin harus memenuhi kriteria penggunaan obat yang rasional. Kriteria obat rasional antara lain ketepatan pemilihan obat, ketepatan dosis obat, tidak adanya efek samping, tidak adanya kontraindikasi, tidak adanya interaksi obat, dan tidak adanya polifarmasi (Muharni, 2015). Penelitian tentang swamedikasi di kalangan mahasiswa pernah dilakukan sebelumnya di beberapa negara selain Indonesia. Penelitian di Uni Emirat Arab yang dilakukan di sebuah Universitas, namun dilakukan pada mahasiswa non kesehatan menunjukkan prevalensi swamedikasi sebesar 59\% (Sharif dan Sharif, 2014). Penelitian lain yang terbaru di Saudi Arabia menunjukkan bahwa prevalensi swamedikasi di kalangan mahasiswa cukup tinggi yaitu $64,8 \%$. Hasil tersebut menunjukkan prevalensi swamedikasi mahasiswa medis (66\%) lebih tinggi daripada mahasiswa non medis (60\%) (Aljaouni et al., 2015). Salah satu penyakit yang bisa dilakukan pengobatan sendiri (swamedikasi) adalah penyakit diare.

Penyakit diare sampai dengan saat ini masih termasuk masalah kesehatan terbesar dunia apalagi bagi negara-negara berkembang karena angka kesakitan dan kematian yang masih tinggi. Pada tahun 2009, The 


\begin{abstract}
United Nations Chlidren Fund (UNICEF) dan World Health Organization (WHO) melaporkan bahwa Asia Selatan merupakan benua tertinggi yang menderita diare pada balita yakni sebesar 783 juta, kemudian Afrika sebesar 696 juta, sebagian dari dunia sebesar 480 juta dan Asia Timur dan Pasifik sebesar 435 juta. Pada tahun 2015 lebih dari 1.400 anak-anak meninggal setiap hari, atau sekitar 526.000 anak per tahun yang disebabkan karena diare. (Ariani, 2016)
\end{abstract}

Berdasarkan Profil Kesehatan Indonesia tahun 2015, terjadi 18 kali KLB diare yang tersebar di 11 provinsi, 18 kabupaten/kota, dengan jumlah penderita 1.213 orang dan kematian 30 orang (CFR 2,47\%). Angka kesakitan nasional hasil Survei Morbiditas Diare tahun 2015 yaitu sebesar 214/1.000 penduduk. Maka diperkirakan jumlah penderita diare di fasilitas kesehatan sebanyak 5.097.247 orang, sedangkan jumlah penderita diare yang dilaporkan ditangani di fasilitas kesehatan sebanyak 4.017.861 orang atau $74,33 \%$ (dengan target 100\%) (Kemenkes RI, 2015). Sedangkan tahun 2016, perkiraan diare di fasilitas kesehatan meningkat sebanyak 6.897 .463 orang dan diare yang ditangani di fasilitas kesehatan sebanyak 2.544.084 orang atau $36,9 \%$ (Kementerian Kesehatan RI, 2016).

Menurut data Dinas Kesehatan Pangkalan Bun pada tahun 2018 2019, diketahui bahwa diare termasuk 10 penyakit terbesar di daerah Pangkalan Bun, Kalimantan Tengah. Kasus diare pada tahun 2018 -2019 yang terjadi di Pangkalan Bun dengan total 2840, data tersebut diperoleh dari 4 Puskesmas di Kotawaringin Barat yaitu Puskesmas Mendawai, Puskesmas Madurejo, Puskesmas Pangkalan Lada dan Puskesmas Pandu Sanjaya. Untuk mengatasi masalah kasus diare yang terjadi tersebut maka perlu adanya kesadaran masyakat terkait bahaya diare. Hal ini dapat dicapai jika diketahui tingkat pengetahuan dan jenis informasi yang belum banyak diketahui serta sikap masyarakat terhadap diare (Dinkes, 2018).

Penelitian ini bertujuan untuk mengetahui tingkat pengetahuan tentang swamedikasi, rasionalitas penggunaan obat pada pasien diare di apotek Kelurahan Mendawai Pangkalan Bun, dan untuk mengetahui hubungan faktor sosiodemografi seperti usia, jenis kelamin, pekerjaan dan pendidikan terakhir.

\section{Metode Penelitian}

Penelitian ini menggunakan metode deskriptif, menggunakan desain penelitian cross-sectional.

\section{Populasi dan sampel}

Populasi dalam penelitian ini adalah seluruh pasien di tiga apotek Kelurahan Mendawai dengan usia 18-59 tahun yang datang untuk melakukan swamedikasi. Berdasarkan data yang diperoleh dari tiga apotek yang menjadi tempat penelitian, jumlah pasien diare perbulan di Apotek H. Imam Syafi'i (60 pasien), di Apotek Pondok Sehat (72 pasien) dan di Apotek Sehat Jaya (75 pasien), sehingga diperoleh jumlah pasien diare di tiga apotek adalah 207 pasien.

\section{Kriteria inklusi dan eksklusi}


Kriteria inklusi dalam penelitian ini adalah pasien diare dengan usia 18-59 tahun dan melakukan swamedikasi di apotek. Sedangkan kriteria eksklusinya adalah pasien yang tidak termasuk dalam kriteria inklusi penelitian ini.

\section{Pengambilan data}

Sumber data dalam penelitian ini yaitu data primer yang diperoleh secara langsung dari responden melalui pengisian kuesioner. Kuesioner dalam penelitian ini terdiri dari 4 bagian, yaitu bagian pendahuluan untuk mengetahui: apakah pasien pernah menggunakan obat swamedikasi, bagian pengetahuan swamedikasi bertujuan untuk mengetahui tingkat pengetahuan pasien tentang swamedikasi, bagian rasionalitas swamedikasi bertujuan untuk mengetahui rasionalitas obat diare yang digunakan responden dan bagian data demografi responden yang bertujuan untuk mengetahui karakteristik responden. Kuesioner yang digunakan sebelumnya dilakukan uji validitas dan reliabilitas.

\section{Analisis data}

Tingkat pengetahuan dibagi menjadi 3 kategori yaitu tingkat pengetahuan baik (skor >76\%), sedang (skor 56\%-75\%) dan buruk (skor $<56 \%$ ). Sedangkan rasionalitas dikategorikan menjadi 2 yaitu rasional jika memenuhi enam kriteria ketepatan pengobatan sendiri dan tidak rasional jika tidak memenuhi enam kriteria ketepatan pengobatan sendiri. Dilakukan pengolahan data menggunakan SPSS. Analisis data dilakukan melalui 2 tahap, yaitu analisis univariat, digunakan untuk mendapatkan gambaran distribusi frekuensi karakteristik demografi dan variabel lain. Analisis bivariat, digunakan untuk mengetahui hubungan sosiodemografi dengan tingkat pengetahuan tentang swamedikasi menggunakan uji chisquare.

\section{Hasil dan Pembahasan Karakteristik Responden}

Sebanyak 207 responden yang terlibat dalam penelitian ini. Berdasarkan hasil penelitian ini, responden didominasi oleh laki-laki (55\%) dengan golongan umur antara 18-28 tahun $(35,2 \%)$ dan mayoritas pendidikan terakhir adalah SMA $(53,7 \%)$ dengan kategori pekerjaan yang paling banyak adalah karyawan swasta $(28,1 \%)$. Karakteristik responden dapat dilihat pada Tabel 1.

Tabel 1. Karakteristik Responden

\begin{tabular}{lcc}
\hline \multicolumn{1}{c}{ Variabel } & Jumlah & $(\%)$ \\
\hline Usia & 73 & $35,2 \%$ \\
\hline a. 18-28 tahun & 55 & $26,6 \%$ \\
\hline b. 29-39 tahun & 36 & $17,4 \%$ \\
\hline c. 40-49 tahun & 43 & $20,8 \%$ \\
\hline
\end{tabular}

d. 50-59 tahun

Jenis Kelamin

\begin{tabular}{lcc}
\hline a. Laki-laki & 114 & $55 \%$ \\
\hline b. Perempuan & 93 & $45 \%$ \\
\hline
\end{tabular}

Pendidikan

Terakhir

\begin{tabular}{lcc}
\hline SD & 19 & $9,1 \%$ \\
\hline SMP & 28 & $13,5 \%$ \\
\hline SMA & 111 & $53,7 \%$ \\
\hline Perguruan Tinggi & 49 & $23,7 \%$ \\
\hline Pekerjaan & & \\
\hline Karyawan Swasta & 58 & $28,1 \%$ \\
\hline Tidak bekerja & 41 & $19,9 \%$ \\
\hline Wirausaha & 37 & $17,9 \%$ \\
\hline Pegawai Negeri & 35 & $16,9 \%$ \\
\hline Mahasiswa & 21 & $10,1 \%$ \\
\hline Pelajar & 7 & $3,3 \%$ \\
\hline Tenaga Kesehatan & 5 & $2,4 \%$ \\
\hline
\end{tabular}




\begin{tabular}{lll}
\hline Guru & 3 & $1,4 \%$ \\
\hline
\end{tabular}

\section{Sumber Informasi Memperoleh Obat Swamedikasi}

Berdasarkan hasil penelitian ini dapat diketahui bahwa mayoritas responden melakukan swamedikasi berdasarkan pengalaman pribadi / keluarga $(57,90 \%)$.

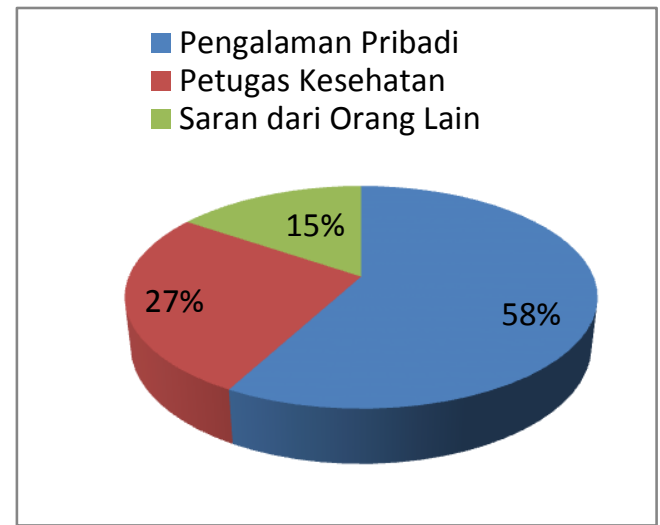

\section{Gambar 1. Sumber Informasi Obat}

\section{Pilihan Farmakologi Obat}

Berdasarkan tabel 2 golongan obat yang paling banyak digunakan pasien di Apotek Kelurahan Mendawai untuk pengobatan swamedikasi diare yaitu golongan obat bebas sebanyak 149 pasien $(71,9 \%)$ dan jamu sebanyak 58 pasien $(28,1 \%)$.

Tabel 2. Obat dan Golongan Obat

\begin{tabular}{lccc}
\hline \multicolumn{1}{c}{$\begin{array}{c}\text { Nama } \\
\text { Obat }\end{array}$} & Golongan & Jumlah & $\mathbf{( \% )}$ \\
\hline Entrostop & Obat Bebas & 69 & \\
Neo & Obat Bebas & 33 & \\
Diaform & Obat Bebas & 31 & 71,9 \\
Oralit & Obat Bebas & 16 & \\
Guanistrep & Jamu & 58 & 28,1 \\
Diapet & & 207 & 100 \\
\hline Total & & & \\
\hline
\end{tabular}

Berdasarkan hasil penilaian mengenai tingkat pengetahuan, dapat diketahui bahwa mayoritas tingkat pengetahuan pasien tergolong sedang yaitu 56,5\%. Data lengkap dapat dilihat pada Tabel 3.

Tabel 3. Frekuensi Tingkat Pengetahuan Seluruh Responden

\begin{tabular}{lcc}
\hline Kriteria & $\begin{array}{c}\text { Jumlah } \\
\text { Pasien }\end{array}$ & Persentase \\
\hline Buruk & 7 & $3,4 \%$ \\
Sedang & 117 & $56,5 \%$ \\
Baik & 83 & $40,1 \%$ \\
\hline Total & 207 & $100 \%$ \\
\hline
\end{tabular}

Sebagian besar pertanyaan yang diberikan tidak dapat dijawab dengan benar oleh responden. Mayoritas responden menjawab dengan baik mengenai pertanyaan pengertian indikasi obat $(68,1 \%)$. Kemudian diikuti pengetahuan pasien mengenai kegunaan oralit $(64,3 \%)$ dan mengenai pengertian kontraindikasi obat $(63,3 \%)$. Tetapi responden paling sedikit menjawab dengan baik pertanyaan tentang definisi swamedikasi $(35,7 \%)$ dan logo obatobatan $(47,8 \%)$. Hal ini karena kurangnya pengetahuan responden mengenai resiko dari pengobatan yang tidak tepat sehingga menganggap informasi tentang obat tidak begitu penting. Oleh karena itu, upaya untuk membekali masyarakat agar mempunyai keterampilan mencari informasi obat secara tepat dan benar perlu dilakukan (Harahap, 2015). Keterangan lebih lanjut dapat dilihat pada tabel 4 .

\section{Tingkat Pengetahuan Responden Tentang Swamedikasi}


Tabel 4. Distribusi Pengetahuan Responden tentang Swamedikasi

\begin{tabular}{cllll}
\hline \multirow{2}{*}{ No } & \multicolumn{1}{c}{ Soal } & \multicolumn{3}{c}{ Jawaban } \\
\cline { 3 - 5 } & & Benar (\%) & Salah (\%) & Tidak Tahu (\%) \\
\hline 1. & Definisi swamedikasi & $74(35,7)$ & $26(12,6)$ & $107(51,7)$ \\
\hline 2. & Logo obat - obatan & $99(47,8)$ & $31(15)$ & $77(37,2)$ \\
\hline 3. & Kegunaan oralit & $133(64,3)$ & $16(7,7)$ & $58(28)$ \\
\hline 4. & Aturan pakai obat & $111(53,6)$ & $77(37,2)$ & $19(9,2)$ \\
\hline 5. & $\begin{array}{l}\text { Aturan pakai obat setiap } 8 \\
\text { jam }\end{array}$ & $114(55,1)$ & $41(19,8)$ & $52(25,1)$ \\
\hline 6. & Pengertian indikasi obat & $141(68,1)$ & $25(12,1)$ & $41(19,8)$ \\
\hline 7. & $\begin{array}{l}\text { Pengertian kontra indikasi } \\
\text { obat }\end{array}$ & $131(63,3)$ & $20(9,7)$ & $56(27,1)$ \\
\hline 8. & $\begin{array}{l}\text { Pengertian efek samping } \\
\text { obat }\end{array}$ & $117(56,5)$ & $35(16,9)$ & $55(26,6)$ \\
\hline 9. & Pengertian interaksi obat & $107(51,7)$ & $26(12,6)$ & $74(35,7)$ \\
\hline 10. & Aturan penyimpanan obat & $118(57)$ & $45(21,7)$ & $44(21,3)$ \\
\hline
\end{tabular}

\section{Rasionalitas Penggunaan Obat dalam Swamedikasi}

Berdasarkan hasil penilaian mengenai rasionalitas penggunaan obat, dapat disimpulkan bahwa mayoritas responden di tiga apotek menggunakan obat secara rasional (63\%). Pengggunaan obat yang rasional merujuk pada penggunaan obat yang benar, sesuai dan tepat.

Penggunaan obat di sarana pelayanan kesehatan umumnya belum rasional. Oleh karena itu, diperlukan adanya suatu promosi penggunaan obat yang rasional dalam bentuk komunikasi, informasi dan edukasi yang efektif dan terusmenerus yang diberikan kepada tenaga kesehatan dan masyarakat melalui berbagai media. (Rahmayanti, 2017).

Penggunaan obat yang tidak rasional paling banyak disebabkan oleh efek samping obat (37\%). Efek samping yang paling umum dialami responden adalah kembung, pusing, rasa tidak nyaman diperut. Efek samping seperti itu banyak dirasakan pasien yang menggunakan obat entrostrop, neo diaform dan guanistrep. Sebelumnya pasien sudah pernah menggunakan obat entrostop, neo diaform, guanistrep dan menyebabkan pasien mengalami efek samping. Dikarenakan pasien tidak membaca keterangan efek samping pada kemasan obat, tetapi merasakan gejala efek samping tersebut. Serta pasien kurang mendapatkan informasi mengenai efek samping obat dari apoteker. Lebih jelasnya dapat dilihat pada Tabel 5 dan Tabel 6.

Tabel 5. Frekuensi Rasionalitas Penggunaan Obat Diare

\begin{tabular}{lcc}
\hline \multicolumn{1}{c}{ Kategori } & Jumlah & Persentase \\
\hline $\begin{array}{l}\text { Tidak } \\
\text { rasional }\end{array}$ & 76 & $37 \%$ \\
Rasional & 131 & $63 \%$ \\
\hline Total & 207 & $100 \%$ \\
\hline
\end{tabular}


Tabel 6. Rasionalitas Penggunaan Obat

\begin{tabular}{cllc}
\hline No & Evaluasi Rasionalitas Obat & Jumlah & Persentase \\
\hline & Rasional & & \\
\hline 1 & Tepat Pemilihan Obat & 207 Pasien & $100 \%$ \\
\hline 2 & Tepat Indikasi & 207 Pasien & $100 \%$ \\
\hline 3 & Tepat Dosis & 207 Pasien & $100 \%$ \\
& - Tepat Aturan Pakai & 207 Pasien & $100 \%$ \\
& - Tepat Lama Pemberian & 207 Pasien & $100 \%$ \\
\hline 4 & Kontra indikasi & 207 Pasien & $100 \%$ \\
\hline 5 & Interaksi Obat & & \\
\hline$\quad$ Tidak Rasional & 76 Pasien & $37 \%$ \\
\hline 6 & Waspada Efek Samping & \\
\hline & Tepat Informasi & 51 Pasien & $32 \%$ \\
7 & - Pasien membaca keterangan obat & 66 Pasien & \\
& - Apoteker / TTK menyampaikan & &
\end{tabular}

Berdasarkan penelitian ini juga dapat diketahui bahwa tingkat pengetahuan mempunyai hubungan dengan usia (nilai $\mathrm{p}=0,016$ ), pendidikan terakhir (nilai $\mathrm{p}=0,000$ ) dan pekerjaan (nilai $\mathrm{p}=0,000)$. Kesimpulan tersebut didasari oleh nilai $(\mathrm{p}<0,05)$ ketiga variabel faktor demografi pada uji chi-square.

\section{Kesimpulan}

1. Tingkat pengetahuan pasien tentang swamedikasi di tiga apotek Kelurahan Mendawai Pangkalan Bun, mayoritasnya adalah tingkat pengetahuan tergolong sedang (56,5\%).

2. Rasionalitas penggunaan obat pada pasien diare di tiga apotek Kelurahan Mendawai Pangkalan Bun yaitu Rasional (63\%) dan tidak rasional (37\%).

3. Faktor-faktor demografi yang mempengaruhi tingkat pengetahuan swamedikasi pasien di tiga apotek Kelurahan Mendawai Pangkalan Bun yaitu usia dengan nilai $(0,016)$, pendidikan terakhir dengan nilai
$(0,000)$ dan pekerjaan dengan nilai $(0,000)$.

5. Saran

1. Dinas Kesehatan Kotawaringin Barat perlu memberikan promosi mengenai cara memilih dan menggunakan obat dengan benar dan tepat.

2. Diharapkan kepada mahasiswa farmasi, apotek ataupun tenaga kesehatan lainnya agar lebih aktif dalam pengabdian masyarakat dan melakukan penyuluhan kepada masyarakat tentang pengetahuan swamedikasi dan rasionalitas obat.

3. Diharapkan kepada masyarakat agar lebih mencari informasi tentang obat-obatan dari sumber yang dapat dipercaya khususnya petugas kesehatan.

4. Pada penelitian tentang kualitas hidup selanjutnya diharapkan agar peneliti dapat menambahkan faktor-faktor yang dapat mempengaruhi tingkat pengetahuan dan rasionalitas obat 
seperti sikap dan penghasilan masyarakat.

\section{Daftar Pustaka}

Alfa, I. Persepsi Pasien Terhadap Pelayanan Swamedikasi oleh Apoteker di beberapa Apoteker Wilayah Surabaya Selatan. 2015;4(2):2

Aljaouni, dkk, 2015. Self-medication Practice Among Medical and Non-medical Students at Taibah University, Madinah, Saudi Arabia.International of Journal Academic Scientific Research,Vol. 3 (4): 54-55

Ariani, P (2016). Diare pencegahan dan pengobatan. Yogyakarta: Nuha Medika

Badan Pusat Statistik [BPS]. 2016. Statistik Daerah Kecamatan Umbulharjo 2016: Badan Pusat Statistik Kota Yogyakarta.

Dinkes, 2018. 10 Penyakit Terbesar di Daerah Pangkalan Bun. Kalimantan Tengah: Dinas Kesahatan Kotawaringin Barat.

Harahap, N. A. (2015). Tingkat Pengetahuan dan Rasionalitas Swamedikasi di Tiga Apotek Kota Panyabungan. Skripsi. Medan: Fakultas Farmasi Universitas Sumatera Utara.

Kemenkes RI. (2015). Pemahaman Masyarakat Akan Penggunaan Obat Masih Rendah. Jakarta: Pusat Komunikasi Publik.

Kementerian Kesehatan Republik Indonesia. (2016). Profil kesehatan di Indonesia tahun
2015. Jakarta: Kementerian Kesehatan Republik Indonesia.

Muharni, S., Fina, A., dan Maysharah, M. (2015). Gambaran Tenaga Kefarmasian dalam Memberikan Informasi Kepada Pelaku Swamedikasi di Apotek-Apotek Kecamatan Tampan, Pekanbaru. Jurnal Sains Farmasi \& Klinis. 2(1): 47-53.

Rahmayanti, E. (2017). Tingkat Pengetahuan dan Rasionalitas Swamedikasi pasien di Tiga Apotek Kecamatan Medan Sunggal. Skripsi. Medan: Fakultas Farmasi Universitas Sumatera Utara.

Sharif, \& Sharif, R.S. 2014. Selfmedication Among NonHealthcare Students of the University of Sharjah United Arab Emirates. Archieve of Pharmacy Practice.Vol. 5 (1): 35-41

Syukron A, Hasan N. Perancangan Sistem Informasi Rawat Jalan Berbasis Web Pada Puskesmas Winong. Bianglala Inform. 2015;3. 